ISSN 1817-3721, E-ISSN 1818-8745

Plant Tissue Cult. \& Biotech. 29(1): 49-62, 2019 (June)

CBangladesh Assoc. for Plant Tissue Culture \& Biotechnology

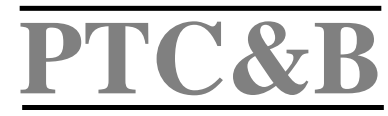

\title{
In vitro Seed Germination, Protocorm Formation and Plantlet Regeneration in Aerides ringens Fisher.
}

\author{
Ashok N. Pyati* \\ Plant Tissue Culture Laboratory, Department of PG Botany, Maharani's Science College for \\ Women, JLB Road, Mysore-570 005, Karnataka, India \\ Key words: In vitro seed germination, Protocorms, Aerides ringes, PGRs
}

\begin{abstract}
An attempt was made to in vitro seed germination and plantlet regeneration in Aerides ringens, a threatened, endemic and epiphytic orchid. Five basal media Knudson $\mathrm{C}(\mathrm{KC})$, Vacin and Went $(\mathrm{VW})$, Burgeff's $\left(\mathrm{N}_{3} \mathrm{f}\right)$, half strength MS, MS were examined for their effectiveness. Germination occurred in all the media. However, KC medium proved to be the best for seed germination $(70.8 \%)$ and half strength MS was superior for the differentiation of protocorm like bodies (PLBs) into seedlings. The seeds were also cultured on various plant growth regulators (PGRs) to evaluate their effectiveness on seed germination and further differentiation. Among the PGRs tested, $0.57 \mu \mathrm{M}$ IAA (IAA $89.3 \%), 4.64 \mu \mathrm{M} \mathrm{Kn}(88.6 \%)$ and $2.21 \mu \mathrm{M}$ BAP $(90.7 \%)$ and $0.57 \mu \mathrm{M}$ IAA + 0.55 $\mu \mathrm{M}$ BAP $(96.5 \%)$ were stimulated the germination and further differentiation of PLBs into seedlings. The concentrations of $2.21 \mu \mathrm{M}$ BAP and combination of $0.57 \mu \mathrm{M}$ IAA +0.55 $\mu \mathrm{M}$ BAP stimulated the formation of MPLBs, which later differentiated into shoots and roots. Four potting substrates were evaluated for Ex vitro seedling survivability of which brick: charcoal: decaying litter: coconut husk $(1: 1: 1: 1)$ gave maximum survival rate $(89.0 \%)$.
\end{abstract}

\section{Introduction}

Orchidaceae is one of the fascinating families among the angiosperms, because of their flower architecture. Orchids are natural, distinctive and highly advanced group of flowering plants with 20,000 - 30,000 species (Chugh et al. 2009). This family is recognized as an economically important commodity in the international floriculture industry both as cut flowers and potted plants (Arditti 1992). Among various species in the family, Aerides genera, commonly called as Cat's tail orchid is one of the popular

*Author for correspondence: <drashoknpyati@gmail.com>. DOI: https://doi.org/10.3329/ptcb.v29i1.41978 
orchid due to showy fragrant racemes with colorful flowers. However, many of the orchids in the wild are experiencing steady diminution in number, becoming rare, because of environmental disruption, succession of natural habitats and over exploitation for ornamental purposes and reduction in the number of natural pollinators (Machaka et al. 2012). At present most of the wild orchids are listed in the International Union of Conservation of Nature and Natural resources (IUCN) Red Data Book. This family is also included in the Appendix-II of the Convention of International Trade in Endangered Species of Wild flora and fauna . Aerides ringens is a threatened, endemic and epiphytic orchid and it is fast depleting species in the Western Ghats of Karnataka, India. A. ringens is horticulturally important owing to the great specialization in structure, colour and longevity of flowers. Normally $A$. ringens reproduces vegetatively by producing off shoots, but this natural way of propagation is generally hampered by very slow division of off shoots. So the rate of production of young plants is time consuming. Hence for conservation and commercial cultivation of this species, an efficient In vitro propagation is necessary. Orchid seeds are microscopic produced profusely $(2.0-3.0$ million per capsule), but are non endospermic and contain almost no nutrients. In nature, for germination and early developmental stages they must be symbiotic with highly specialized fungi (Swarts and Dixon 2009), consequently $<5 \%$ of the seeds germinate in the wild habitats.

Now the asymbiotic seed germination technique is utilized for the production of many orchids and it is shown to be an efficient tool for the production of orchids for conservation and reintroduction into their natural habitats (Kauth et al. 2006, Stewart and Kane 2006). The main objective of the experiment on this species is to develop efficient mass propagation protocol, the most suitable media composition and supplements for seed germination, regeneration through protocorm like bodies and consequently on the ex vitro acclimatization process.

\section{Materials and Methods}

Plants of Aerides ringens were collected from Anekadu of Coorg district in Karnataka, India during October-November, 2012 and grown in a greenhouse at the Plant Tissue Culture Laboratory, Department of PG Botany, Maharani's Science College for Women, Mysore, Karnataka, India. Flowers were hand pollinated in order to get sufficient capsules. Capsules were harvested as they turned green to yellowish green (after five and a half months of pollination), were washed with detergent and soaked in $0.5 \%$ sodium hypochlorite for $10 \mathrm{~min}$, rinsed thoroughly twice with sterile distilled water, dipped in $70 \%(\mathrm{v} / \mathrm{N})$ ethanol for $45 \mathrm{sec}$ and flamed. The surface sterilized capsules were then cut opened using sterile surgical blade and seeds were removed.

The seeds were spread as thin films in test tubes containing $15 \mathrm{ml}$ of five basal media viz., MS, Knudson C (KC 1946), Burgeff's N ${ }_{3} f\left(N_{3} f\right.$ 1936) and Vacin and Went (VW 1949) 
and half strength MS, with addition of $2 \%$ sucrose, $0.8 \%$ TC ${ }^{\circledR}$ agar (Hi media, Mumbai, India), to assess their effect on seed germination. All the media were adjusted to $\mathrm{pH} 5.8$ using $1 \mathrm{~N} \mathrm{NaOH}$ before the addition of agar, then sterilized at $1.2 \mathrm{Kg} \mathrm{cm}^{-2}$ and $121^{\circ} \mathrm{C}$ for $15 \mathrm{~min}$. The culture tubes were incubated at $24 \pm 2^{\circ} \mathrm{C}$ under $12 \mathrm{hrs}$ photoperiod provided

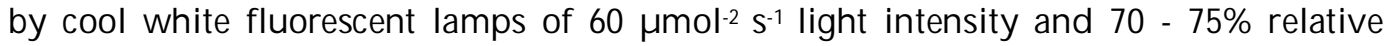
humidity.

Different developmental stages of asymbiotically cultured Aerides ringens seeds and seedlings are as follows.

\begin{tabular}{ll}
\hline Stage number & Development of orchid \\
\hline 0 & Fertile seeds having hyaline embryo covered with testa seed coat. \\
I & Germinated seeds, embryo swollen but still covered with testa/seed coat. \\
II & Embryo greatly swollen forming sphere shaped protocorms with rhizoids \\
& without testa/seed coat. \\
III & Protocorms with shoot primordia/protomeristem with rhizoids. \\
IV & Protocorms with emergence of $1-2$ leaves. \\
V & Complete plantlets with shoot and roots. \\
\hline
\end{tabular}

After attaining the height of the plantlet within $4-5 \mathrm{~cm}$, it were removed from the culture bottles and washed thoroughly with slow running tap water, to remove the adherent of the medium. Then they were transplanted to four different substrates - (a) pieces of brick: charcoal pieces: vermiculite $(1: 1: 1)$, (b) pieces of brick: charcoal pieces: coconut husk ( $1: 1: 1)$, (c) pieces of brick: charcoal pieces: decaying litter: coconut husk (1 $: 1: 1: 1)$ and (d) pieces of brick: charcoal pieces: decaying litter: vermiculite $(1: 1: 1: 1)$ to evaluate their survivability. The cultures were maintained for $3-4$ weeks at $12 / 12 \mathrm{hrs}$ photoperiod with light provided at $40 \mathrm{\mu molm}^{-2} \mathrm{~s}^{-1}$ intensity at $28 \pm 2^{\circ} \mathrm{C}$ temperature. The relative humidity was maintained at $90 \%$ for the first week and then gradually lowered to $40 \%$ after one week. Then the plantlets were sprayed with diluted 1/10 of MS without sucrose twice a week for one and a half months.

Percentage of germination in each stage was calculated for each treatment by dividing the number of germinated seeds in each stage by the total number of viable seeds in each sample. The mean values of the various treatments were subjected to ANOVA. The difference between the mean of each treatment was scored using Tukey test at $\mathrm{p}$ value $<0.05$.

\section{Results and Discussion}

After 3 - 4 weeks of culture, the seeds started imbibing the nutrients, increased in size and reached (stage 1). The speed and extent of germination and protocorm formation 
(stage 2) differs with the medium used. The highest percentages at stage 1 and 2 development with respect to germination were observed on $\mathrm{KC}$ medium $(70.8 \%)$. This was significantly higher than all other media treatments investigated. In this medium soon after passing stage 1, the stage 2 began to form after 4 weeks of culture. The PLBs were green and healthy. The fast imbibitions in the $\mathrm{KC}$ medium led into the rupture of testa and emergence of protocorms were high. It was observed that the $\mathrm{KC}$ basal medium was most suitable up to stage 2 development in this species. On the other hand, the seeds inoculated on to the VW medium recorded moderate $47.6 \%$ of germination, $\mathrm{N}_{3} \mathrm{f}$ medium showed $31.0 \%$ of germination, half strength MS medium showed $42.7 \%$ of germination and least germination of $17.3 \%$ was recorded on MS medium. On VW, $1 / 2 \mathrm{MS}, \mathrm{N}_{3} \mathrm{f}$ and MS media, the formation of stage 1 and stage 2 development took more time and the percentage of seed germination was also less, compared to KC medium (Table 1).

Table 1. Effect of different basal media on seed germination and seedling development of $A$. ringens.

\begin{tabular}{|c|c|c|c|c|c|c|c|}
\hline \multirow{2}{*}{$\begin{array}{l}\text { Basal } \\
\text { media }\end{array}$} & \multirow{2}{*}{$\begin{array}{l}\text { Germi- } \\
\text { nation \% }\end{array}$} & \multicolumn{5}{|c|}{ Developmental stages (in weeks) } & \multirow[t]{2}{*}{ Remarks } \\
\hline & & I & II & III & IV & $\mathrm{V}$ & \\
\hline MS & $17.3 \pm 0.73 d$ & 05 & 07 & 14 & 22 & 29 & $\begin{array}{l}\text { Very low germination frequency, } \\
\text { achlorophyllous, protocorm differentiation } \\
\text { most impaired. }\end{array}$ \\
\hline $\mathrm{KC}$ & $70.8 \pm 5.08 a$ & 03 & 04 & 07 & 16 & 20 & $\begin{array}{l}\text { High germination frequency, chlorophyll } \\
\text { development and protocorm } \\
\text { differentiation moderate. }\end{array}$ \\
\hline $\mathrm{N}_{3} \mathrm{f}$ & $31.0 \pm 3.46 c$ & 04 & 06 & 12 & 19 & 27 & $\begin{array}{l}\text { Low to moderate germination frequency } \\
\text { and poor protocorm formation }\end{array}$ \\
\hline VW & $47.6 \pm 1.43 \mathrm{~b}$ & 03 & 06 & 12 & 19 & 27 & $\begin{array}{l}\text { Moderate germination frequency and poor } \\
\text { protocorm formation }\end{array}$ \\
\hline $1 / 2 \mathrm{MS}$ & $42.7 \pm 5.04 b$ & 04 & 05 & 09 & 14 & 18 & $\begin{array}{l}\text { Moderate germination frequency and } \\
\text { protocorm differentiation very high }\end{array}$ \\
\hline
\end{tabular}

Values represent mean \pm standard error; the same letters within a column are not significantly different based on ANOVA followed by Tukey's test at $\mathrm{p}<0.05$.

Interestingly, there was a moderate germination percentage on half strength MS. It was observed that half strength MS was the most suitable, when the stage 2 developed on the KC medium were sub cultured on to half strength MS medium, it stimulated the high frequency differentiation of these into stage 3,4 and stage 5 in 9, 14 and 18 weeks of cultures respectively. These plantlets were of an average $2.0-2.5 \mathrm{~cm}$ in height, having 1 2 roots. The differentiation of stage 2 into stage 3, 4 and stage 5 was superior in half strength MS compared with all other treatments. When subcultured on the KC medium, the differentiation of stage 2 into stage 3, 4 and stage 5 was recorded to be slow and took 7, 16 and 20 weeks, respectively. The plantlets were having $1-2$ roots and an average of $1.0-1.5 \mathrm{~cm}$ in height. The differentiation of stage 2 was rather slow compared to half strength MS medium. However on VW and $\mathrm{N}_{3}$ f media, the seed germination up to stage 
2 was recorded moderate and differentiation to stage 3, 4 and stage 5 was slow and took 12, 19 and 27 weeks of cultures, respectively. Most of the stage 2 PLBs etiolated, only a few differentiated into stage 3, 4 and stage 5, the plantlets were not so healthy. Rather in MS medium, the seed germination was very slow and only $17.3 \%$ of seeds reached stage 2 in 7 weeks of culture. These PLBs were achlorophyllous and most of them failed to differentiate, subsequently turned brown and necrotic. But, a few of stage 2 developed chlorophyll and differentiated into stage 3, 4 and state 5 seedlings and took 14, 22 and 29 weeks of culture respectively. But the seedlings developed were not healthy.

Based on present results, it was clear that the $\mathrm{KC}$ medium produced optimum seed germination in $A$. ringens as compared to VW, $1 / 2 \mathrm{MS}, \mathrm{N}_{3} \mathrm{f}$ and MS media. Hence KC medium was used for all further experiments. Significant differences among the different media were observed for development of $A$. ringens seeds. The highest frequency of germination at stage 2 of development was observed on KC medium. However the differentiation of this stage 2 into stage 3, 4 and stage 5 seedlings was superior on $1 / 2$ MS medium.

Although, optimum seed germination was recorded on $\mathrm{KC}$ basal medium, then to increase the frequency of seed germination various PGRs were added. IAA, NAA, BAP and $\mathrm{Kn}$ at various concentrations individually and in combinations were fortified to see their effect on seed germination and further development. When the medium was supplemented with IAA at lower concentrations of $0.57 \mu \mathrm{M}$ showed best response. $89.3 \%$ seeds germinated and reached stage 2 in 4 weeks. Further these differentiated into stage 3, 4 and stage 5 in 6,12 and 16 weeks of cultures, respectively. The seedlings were having $2-3$ roots and an average of $2-3 \mathrm{~cm}$ in height. IAA in higher concentrations showed detrimental effect on germination. However, higher concentration of $5.71 \mu \mathrm{M}$ stimulated the formation of larger sized roots (Fig. 2D). The hormone NAA had no effect on seed germination as compared to $\mathrm{KC}$ basal medium. There was a positive effect of $\mathrm{Kn}$ in the percentage of seed germination. The concentration of $4.64 \mu \mathrm{M}$ increased the seed germination up to $88.6 \%$. However the BAP at $2.21 \mu \mathrm{M}$ concentration had tremendous effect on germination frequency $(90.7 \%)$. It was the most effective PGR tested among IAA, NAA and $\mathrm{Kn}$. The seeds imbibed water and nutrients quickly and formed into stage 2 in 4 weeks of culture (Fig. 1A). It not only triggered the germination percentage but also stimulated the conversion of stage 2 into stage 3, 4 and stage 5 very effectively with 6, 12 and 16 weeks of cultures respectively (Tables 2 and 4). The seedlings were larger and healthy, having $2-3$ roots and an average of $2.5-3.5 \mathrm{cms}$ in height.

However, the combination of Auxins and Cytokinins also showed beneficial, neutral and detrimental effect on germination. The KC medium supplemented with IAA and Kn was less stimulative than media supplemented with IAA or Kn alone. The optimum 
germination was recorded on medium containing $0.57 \mu \mathrm{M}$ IAA $+4.64 \mu \mathrm{M} \quad \mathrm{Kn}$. In this combination study, $80.2 \%$ of seeds germinated and reached stage 2 in 5 weeks. These
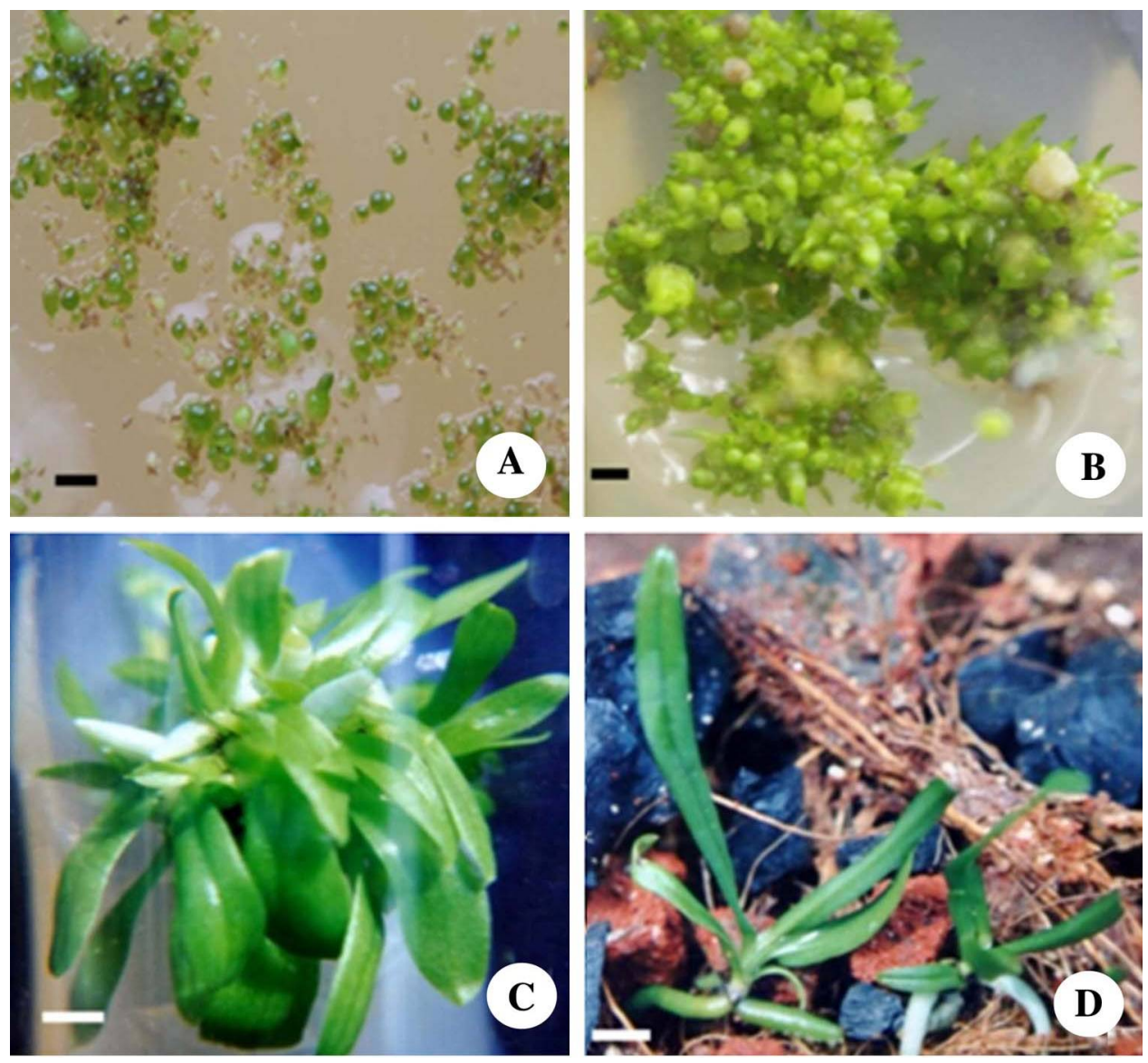

Fig. 1. Asymbiotic seed germination and seedling development of Aerides ringens. A. Formation of PLBs (stage 2) after 4 weeks of culture on $\mathrm{KC}$ medium supplemented with $2.21 \mu \mathrm{M}$ BAP. Scale bar $=0.5 \mathrm{~mm}$. B. Emergence of shoot primordia/promeristems (stage 3) after 6 weeks of culture on KC medium supplemented with $0.57 \mu \mathrm{M}$ IAA $+0.55 \mu \mathrm{M}$ BAP. Scale bar $=1 \mathrm{~mm}$. C. Development of plantlets (stage 5) after 15 weeks of culture on KC medium supplemented with $0.57 \mu \mathrm{M}$ IAA $+0.55 \mu \mathrm{M}$ BAP. Scale bar $=1$ $\mathrm{cm}$. D. Seelings acclimatized in greenhouse. Scale bar $=1 \mathrm{~cm}$.

then differentiated into stage 3, 4 and stage 5 in 7, 14 and 17 weeks respectively. When the IAA concentration was increased in combination with $\mathrm{Kn}$ there was a drastic decrease in the seed germination frequency. The effect of IAA and BAP interaction was stimulative when both were present in the medium. The seed germination was high $(96.5 \%)$ in this combination compared to all other PGR treatments. The interaction between $0.57 \mu \mathrm{M}$ IAA and $0.55 \mu \mathrm{M}$ BAP concentration promoted the stage 2 formation in 4 weeks, PLBs were larger in size compared to other treatments and also they 
differentiated into stage 3 (Fig. 1B), 4 and 5 (Fig. 1C) in 6, 11 and 15 weeks respectively (Table 3 and 4). The formation of stage 2 and differentiation of stage 3, 4 and stage 5 were superior in this combination studied. The seedlings were well grown and healthy, having 2 - 3 roots and an average of $2.5-3.5 \mathrm{~cm}$ in height. In another experiment the KC medium added with NAA and $\mathrm{Kn}$ in different concentrations showed negative effect on germination. The 'stage $0^{\prime}$ viable seeds cultured on this combination imbibed and reached stage 1 but most of them did not reach the stage 2. Hence NAA and Kn combination showed negative effect on seed germination process. Present results showed that NAA and BAP combination had no effect on seed germination when compared to the $\mathrm{KC}$ basal medium.

Table 2. Single effect of plant growth regulators on in vitro response of $A$. ringens seeds in $\mathrm{KC}$ basal medium.

\begin{tabular}{llllll}
\hline IAA & NAA & Kn & BAP & $\begin{array}{l}\text { Per cent of germination } \\
\text { (after 7 weeks) }\end{array}$ & Remarks \\
\hline 0.57 & 0 & 0 & 0 & $89.3 \pm 3.19^{*} \mathrm{a}$ & MPLBs \\
2.85 & 0 & 0 & 0 & $81.3 \pm 1.77 \mathrm{~b}$ & \\
5.71 & 0 & 0 & 0 & $52.0 \pm 3.27 \mathrm{~d}$ & \\
0 & 0.54 & 0 & 0 & $71.0 \pm 3.28 \mathrm{c}$ & \\
0 & 2.69 & 0 & 0 & $70.8 \pm 2.03 \mathrm{c}$ & \\
0 & 5.38 & 0 & 0 & $46.4 \pm 3.74 \mathrm{~d}$ & \\
0 & 0 & 0.46 & 0 & $67.1 \pm 3.83 \mathrm{c}$ & \\
0 & 0 & 2.32 & 0 & $80.2 \pm 3.54 \mathrm{~b}$ & \\
0 & 0 & 4.64 & 0 & $88.6 \pm 2.40^{*} \mathrm{a}$ & \\
0 & 0 & 0 & 0.55 & $86.7 \pm 1.49 \mathrm{a}$ & \\
0 & 0 & 0 & 2.21 & $90.7 \pm 1.84^{*} \mathrm{a}$ & \\
0 & 0 & 0 & 4.42 & $81.8 \pm 3.85 \mathrm{~b}$ & \\
\hline
\end{tabular}

*Optimum \% of germination. Values represent mean \pm standard error; the same letters within a column are not significantly different based on ANOVA followed by Tukey's test at $\mathrm{p}<0.05$.

Yellowish green large sized PLBs were observed on the KC medium supplemented with $2.21 \mu \mathrm{M}$ BAP (Fig. 2A ) and combination of $0.57 \mu \mathrm{M}$ IAA with $0.55 \mu \mathrm{M}$ BAP, after 6 weeks of culture. These yellowish green large sized PLBs lost their shape in 3 - 4 weeks of culture and became irregular subsequently. They started to divide on KC medium supplemented with the above PGRs, and formed green clumps after 10 weeks of culture, having smaller 18 - 20 granules. These further differentiated into multiple protocorm like bodies (MPLBs) (Fig. 2B). These MPLBs further developed and differentiated into shoots after 14 weeks of culture in KC basal medium (Fig. 2C). The multiple shoots, subculturing on the $\mathrm{KC}$ medium fortified with $5.71 \mu \mathrm{M}$ IAA triggered the formation of roots 
(Fig. 2D). Then, these plantlets which developed shoot and roots were successfully transferred to potting media.

Table 3. In vitro response of $A$. ringens seeds on KC basal medium supplemented with plant growth regulators in combination $(\mu \mathrm{M})$.

\begin{tabular}{llllc}
\hline IAA & NAA & Kn & BAP & $\begin{array}{l}\text { Total \% of germination } \\
\text { after 7 weeks }\end{array}$ \\
\hline 0.57 & 0 & 0.46 & 0 & $71.3 \pm 2.50 \mathrm{~cd}$ \\
2.85 & 0 & 2.32 & 0 & $70.6 \pm 3.62 \mathrm{~cd}$ \\
5.71 & 0 & 4.64 & 0 & $41.6 \pm 2.90 \mathrm{e}$ \\
0.57 & 0 & 4.64 & 0 & $80.2 \pm 3.08^{*} \mathrm{c}$ \\
5.71 & 0 & 0.46 & 0 & $50.3 \pm 3.99 \mathrm{e}$ \\
0 & 0.5 & 0.46 & 0 & $3.6 \pm 0.21 \mathrm{f}$ \\
0 & 2.69 & 2.32 & 0 & $4.0 \pm 0.33 \mathrm{f}$ \\
0 & 5.38 & 4.64 & 0 & 00 \\
0 & 0.54 & 4.64 & 0 & 00 \\
0 & 5.3 & 0.46 & 0 & 00 \\
0.57 & 0 & 0 & 0.55 & $96.5 \pm 0.89^{*} \mathrm{a}$ \\
& & & & MPLBs \\
2.85 & 0 & 0 & 2.21 & $80.2 \pm 1.35 \mathrm{c}$ \\
5.71 & 0 & 0 & 4.42 & $80.1 \pm 2.14 \mathrm{c}$ \\
0.57 & 0 & 0 & 4.42 & $87.0 \pm 1.81 \mathrm{~b}$ \\
5.71 & 0 & 0 & 0.55 & $88.6 \pm 2.24 \mathrm{~b}$ \\
0 & 0.54 & 0 & 0.55 & $70.3 \pm 3.65 \mathrm{~cd}$ \\
0 & 2.69 & 0 & 2.21 & $71.0 \pm 3.67 \mathrm{~cd}$ \\
0 & 5.38 & 0 & 4.42 & $69.2 \pm 2.15 \mathrm{~d}$ \\
0 & 0.54 & 0 & 4.42 & $71.5 \pm 1.50 \mathrm{~cd}$ \\
0 & 5.38 & 0 & 0.55 & $68.0 \pm 2.16 \mathrm{~d}$ \\
\hline
\end{tabular}

*Optimum \% of germination. Values represent mean \pm standard error; the same letters within a column are not significantly different based on ANOVA followed by Tukey's test at $\mathrm{p}<0.05$.

After 20 weeks, in vitro grown well developed plantlets of about $4-5 \mathrm{~cm}$ length, having 2 - 3 well developed roots were taken from the cultures. It was acclimatized on four different substrates (Table 5). One of the substrates used is pieces of charcoal, brick pieces, decaying litter and coconut husk in the ratio of $1: 1: 1: 1$ which gave maximum survival rate of $89.0 \%$. During hardening, the transferred plantlets shed 1 - 2 leaves after 3 weeks of transplantation and new leaves emerged after 1 - 2 weeks. This combination of potting medium provided enough moisture, aeration and nutrients for the luxuriant growth of shoot and roots. After 16 weeks of hardening they attained an average height of $6.8 \mathrm{~cm}$ (Fig. 1D). 
Table 4. Optimum germination and protocorm differentiation of $A$. ringens on $\mathrm{KC}$ medium supplemented with plant growth regulators.

\begin{tabular}{|c|c|c|c|c|c|c|c|}
\hline \multirow[t]{2}{*}{ PGR } & \multirow{2}{*}{$\begin{array}{l}\text { Germination } \\
\text { percentage }\end{array}$} & \multicolumn{5}{|c|}{ Developmental stages (in weeks) } & \multirow[t]{2}{*}{ Remarks } \\
\hline & & I & II & III & IV & $\mathrm{V}$ & \\
\hline IAA $(0.57 \mu \mathrm{M})$ & $89.3 \pm 3.19 a$ & 3 & 4 & 6 & 12 & 16 & \multirow[t]{5}{*}{ MPLBs } \\
\hline $\mathrm{Kn}(4.64 \mu \mathrm{M})$ & $88.6 \pm 2.40 \mathrm{a}$ & 3 & 5 & 7 & 14 & 17 & \\
\hline $\operatorname{BAP}(2.21 \mu \mathrm{M})$ & $90.7 \pm 1.84 a$ & 3 & 4 & 6 & 12 & 16 & \\
\hline $\begin{array}{l}\mathrm{IAA}+\mathrm{Kn} \\
(0.57 \mu \mathrm{M}+4.64 \mu \mathrm{M})\end{array}$ & $80.2 \pm 3.08 c$ & 3 & 5 & 7 & 14 & 17 & \\
\hline $\begin{array}{l}\text { IAA + BAP } \\
(0.57 \mu \mathrm{M}+0.55 \mu \mathrm{M})\end{array}$ & $96.5 \pm 0.89 a$ & 3 & 4 & 6 & 11 & 15 & \\
\hline
\end{tabular}

Values represent mean \pm standard error; the same letters within a column are not significantly different based on ANOVA followed by Tukey's test at $\mathrm{p}<0.05$.
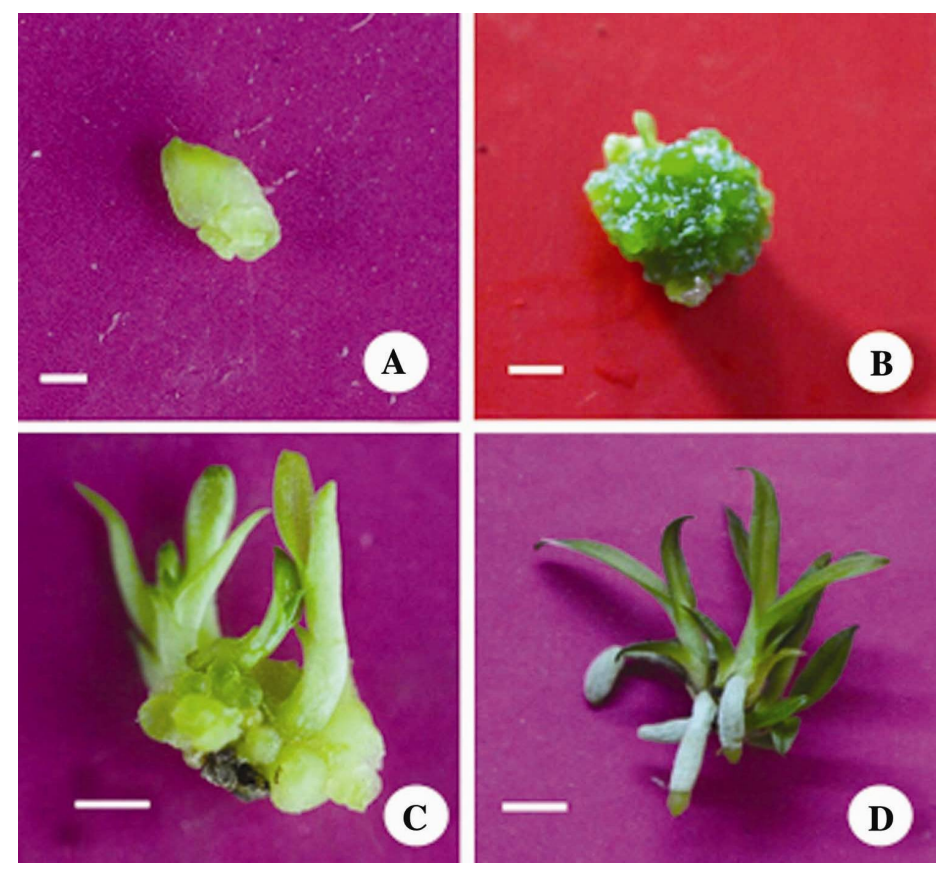

Fig. 2. In vitro regeneration of Aerides ringens through multiple protocorm like bodies. A. Larger PLB developed after six weeks of culture on KC medium supplemented with $2.21 \mu \mathrm{M}$ BAP. Scale bar $=1 \mathrm{~mm}$. B. Formation of MPLBs after 10 weeks of culture on KC medium supplemented with $0.57 \mu \mathrm{M}$ IAA +0.55 $\mu \mathrm{M}$ BAP. Scale bar $=1 \mathrm{~mm}$. C. Subsequent proliferation of MPLBs into shoots after 14 weeks of subculture in $\mathrm{KC}$ basal medium. Scale bar $=1 \mathrm{~cm}$. D. Well developed plantlets after 20 weeks of culture on KC medium supplemented with $5.71 \mu \mathrm{M}$ IAA. Scale bar $1 \mathrm{~cm}$.

The nutritional requirement for orchid seed germination differs from species to species. There is no universal medium for all the orchid species (Arditti and Earnst 1984). The different media examined were MS, 1/2 MS, KC, N3f and VW. The seeds germinated 
on all the nutrient media used in the study, but the percentage of germination and time varied on different media (Table 1). In all the nutrient basal media, the seeds imbibed, and enlarged in size. KC medium was best for germination up to stage 2 development. PLBs formation was significantly high and fastest with $70.8 \%$ of germination on KC medium. This was followed by $47.6 \%$ on VW, $42.7 \%$ on $1 / 2$ MS, $31.0 \%$ on $\mathrm{N}_{3}$ f and very low germination of $17.3 \%$ on MS media. The high percentage of germination on KC medium was due to the lower concentration of ions of macro and micro salts. The stage 2 development was observed earliest and highest in KC medium after 4 weeks of culture. The high speed and more germination percentage of $A$. ringens on KC medium might have been influenced by the presence of less major and minor salts. The reduced concentrations of inorganic salts had beneficial effect on seed germination in many orchid species (Mitchell 1989, Anderson 1991). The similar beneficial effect of KC medium was also recorded on germination of many orchid species like, Paphiopedilum villosum (BoLong et al. 2010), Vanda hybrid (Johnson and Kane 2007), Coelogyne nervosa (Shibu et al. 2012) and Calopogon tuberosus (Kauth et al. 2006). In contrast, the poor/no response of seed germination on KC medium was also reported by some workers in many orchids like Dendrobium longicornu and D. formosum (Dohling et al. 2008), Aerides crispum (Pyati and Murthy 1999), Dactylorhiza hatagirea (Warghat et al. 2014), Limodorum abortivum (Sgarbi et al. 2009) and Cymbidium bicolor (Mahendran et al. 2013).

Table 5. Acclimatization of Aerides ringens seedlings after 16 weeks of hardening in Green house conditions.

\begin{tabular}{lcc}
\hline Substrate used & Survival percentage & Height in cm \\
\hline 1. Brick: charcoal: vermiculite $(1: 1: 1)$ & $46 \pm 2.34 \mathrm{c}$ & 4.8 \\
2. Brick: charcoal: coconut husk $(1: 1: 1)$ & $61 \pm 2.23 \mathrm{~b}$ & 4.9 \\
3. Brick: charcoal: decaying litter: coconut husk $(1: 1: 1: 1)$ & $89 \pm 1.73 \mathrm{a}$ & 6.8 \\
4. Brick: charcoal: decaying litter: vermiculite $(1: 1: 1: 1)$ & $68 \pm 2.68 \mathrm{~b}$ & 5.0 \\
\hline
\end{tabular}

Values represent mean \pm standard error; the same letters within a column are not significantly different based on ANOVA followed by Tukey's test at $\mathrm{p}<0.05$.

The stimulative effect of the $\mathrm{KC}$ medium on germination frequency may be due to relatively high calcium concentration compared to other media. The calcium significantly influences plant growth and cell karyokinesis, this correlates the earlier work on Paphiopedilum species (BoLong et al. 2010). The VW, half strength MS and N3f media showed moderate germination because of the presence of low salt concentrations. However the germination percentage was documented to be very poor on MS because of excessively high concentrations of major and minor salts that inhibited germination in A. ringens, and this correlates the earlier work on various orchid species (Shibu et al. 2012, Manrique and Gutierrez 2006). On the other hand the beneficial effect of MS was 
also reported by many researchers on Coelogyne nervosa (Abraham et al. 2012), Coelogyne suaveolens (SungKumlong and Deb 2008) and Laelia speciosa (Diaz et al. 2009).

In the present experiment higher frequency of germination of stage 2 was observed in $\mathrm{KC}$ medium. However when this stage 2, was subcultured on half strength MS the differentiation into stage 3, 4 and 5 was high. It clarifies that optimum germination medium may not be the best medium for subsequent differentiation of PLBs into seedlings. It shows that the different stages of development require different nutritional supplements. Similar results were also reported for differential nutrition by later stages of germination and seedling growth in Bletia purpurea (Dutra et al. 2008), Calopogon tuberosus (Kauth et al. 2008) and Cephalanthera falcata (Yamazaki and Miyoshi 2006). Further, future research should investigate such type of differential nutritional requirements for different stages of germination and subsequent development.

Plant growth regulators have profound effect on seed germination, formation of protocorms and differentiation into seedlings. To enhance the growth, the medium was supplemented with various PGRs. A. ringens seeds which were germinated on KC medium fortified with IAA alone at concentration of $0.57 \mu \mathrm{M}$ showed positive effect on germination. It is in accordance with the earlier work on Orchis coriophora (Bektas et al. 2013), but at its higher concentrations of $5.71 \mu \mathrm{M}$ showed inhibitory effect on germination. However, when the plantlets of stage 4 were cultured on the higher concentrations of IAA it induced very good rooting system and this correlates with earlier work on Epidendrum ibaguense (Hossain 2008). The seeds cultured on KC medium supplemented with $\mathrm{Kn}$ at $4.64 \mu \mathrm{M}$ showed stimulative effect on germination. It is in conformity with the earlier work on Comparettia falcata (Manrique et al. 2005). When NAA was added to the KC medium it had no effect on germination. The seeds germinated in normal way as compared to KC basal medium. Similar results were recorded earlier on Odontoglossum gloriosum (Manrique and Gutierrez 2006) where lower concentration of NAA did not show any positive effect on germination but higher concentration at $5.38 \mu \mathrm{M}$ showed retardive effect. However the most stimulative effect was observed when the KC medium was supplemented with BAP. The concentration of $2.21 \mu \mathrm{M}$ stimulated the seeds to form stage 2 in 4 weeks. The protocorms were large and dark green. Their proliferation into stage 3, 4 and 5 were faster and seedling growth was luxuriant when cultured on the same medium. BAP was the most potent stimulator of germination and proliferation studied among the PGRs in our experiment. Similar effect of BAP was also recorded in Dendrobium primulinum (Pant and Thapa 2012) and Eulophia nuda (Nanekar et al. 2014).

The combination of auxin with cytokinin showed positive, negative and neutral effects on seed germination process, but IAA and Kn combination was less stimulative in the germination frequency and there was a remarkable antagonism between IAA and Kn. The similar observation was made in Comparettia falcata (Manrique et al. 2005). The 
combination between NAA and Kn showed negative effect on germination. This combination inhibited the seed germination which became almost nil. However, the same combination stimulated the regeneration of plantlets from calli in Dendrobium cv. Serdang Beauty (Khosravi et al. 2008). NAA in combination with BAP had no effect on seed germination and the results obtained in this combination were almost similar with that of $\mathrm{KC}$ basal medium. When the seeds of $A$. ringens were cultured on $0.57 \mu \mathrm{M}$ IAA and $0.55 \mu \mathrm{M}$ BAP, it stimulated the seed germination frequency in which the stage 2 developed in 4 weeks and these PLBs were dark green and larger in size. This PGR combination triggered the seed germination and seedling development as well and synergistic action of auxin-cytokinin combination was observed. Interestingly some of the larger PLBs divided and formed into MPLBs in this combination of PGR. On subculturing these MPLBs, on KC basal medium developed multiple shoots. These multiple shoots cultured on KC medium fortified with $5.71 \mu \mathrm{M}$ IAA developed larger roots.

Most of the micropropagated plants did not survive, when transferred to ex vitro conditions because of less relative humidity and higher temperature in the environment. Hence $90 \%$ relative humidity was given initially for proper acclimatization, then it was gradually reduced to $40 \%$. Most of the plantlets were replaced by new leaves after 3 weeks of ex vitro transfer. Formation of new shoots during acclimatization of Calapogon tuberosus (Kauth et al. 2006) and Bletia purpurea (Dutra et al. 2008) has also been reported. For well acclimatization three factors-water holding capacity, porosity and drainage are very essential for healthy growth and development of in vitro grown seedlings of orchids. The substrate, pieces of charcoal, brick pieces, decaying litter and coconut husk in the ratio of $1: 1: 1: 1$ gave excellent survival results in which $89 \%$ of seedlings grown very well.

In the present study, an efficient protocol for rapid production of $A$. ringens plants using seeds has been demonstrated. Maximum number of seeds reached stage 2 on KC medium and these subsequently differentiated into stage 3, 4 and 5 on half strength MS. It shows that optimum germination medium may not be the best medium for subsequent development. To enhance the percentage of seed germination various PGRs were also used. The most effective PGRs were BAP at $2.21 \mu \mathrm{M}$ and combination of IAA $0.57 \mu \mathrm{M}$ and BAP $0.55 \mu \mathrm{M}$, which gave excellent results and in these combinations MPLBs also developed. After 20 weeks, the in vitro grown plantlets were hardened under greenhouse conditions on different substrates, of which, brick: charcoal: decaying litter: coconut husk $(1: 1: 1: 1)$ gave maximum survival. Asymbiotic germination and successful Ex vitro establishment of plants are helpful to reintroduce these into their natural habitats or for ornamental purpose. 


\section{Acknowledgements}

The author gratefully acknowledges the financial support provided by the University Grants Commission, New Delhi, India, in the form of Major Research Project F. No. 42$927 / 2013$ (SR) dated: 14/03/2013.

\section{References}

Abraham S, Augustine J and Thomas TD (2012) Asymbiotic seed germination and in vitro conservation of Coelogyne nervosa A. Rich. An endemic orchid to Western Ghats. Physiol. Mol. Biol. Plants 18(3): 245-251.

Anderson AB (1991) Symbiotic and asymbiotic germination and growth of Spiranthes magnicamporum (Orchidaceae). Lindleyana 6(4): 183-186.

Arditti J (1992) Classification and naming of orchids. In: Fundamentals of Orchid Biology, John Willey and Sons Press New York pp. 55-101.

Arditti J and Earnst R (1984) Physiology of germinating orchid seeds: In: Orchid Biology - Reviews and Perspectives, Vol. III edited by Arditti. J. Cornell University Press New York. pp. 177-222.

Bektas E, Cuce M and Sokmen A (2013) In vitro germination, protocorm formation and plantlet development of Orchis coriophora (Orchidaceae) a naturally growing orchid species in Turkey. Turkish J. Bot. 37: 336-342.

BoLong, Niemiera AX, Cheng ZY and Long CL (2010) In vitro propagation of four threatened Paphiopedilum species (Orchidaceae). Plant Cell Tiss. Org. Cult. 101: 151-162.

Chugh S, Guha S and Rao UI (2009) Micropropagation of orchids: A review on the potential of different explants. Scientia Horticult. 122: 507-520.

Diaz IA, Oyama K, Alonso CG and Garciglia RS (2009) In vitro propagation of the endangered orchid Laelia speciosa. Plant Cell Tiss. Org. Cult. 99: 335-343.

Dohling S, Kumaria S and Tanden P (2008) Optimization of nutrient requirements for asymbiotic seed germination of Dendrobium longicornu and D. formosum. Proceedings of the Indian National Science Academy 74: 167-171.

Dutra D, Johnson TR, Kauth PJ, Stewart SL, Kane ME and Richardson L (2008) Asymbiotic seed germination, in vitro seedling development and green house acclimatization of the threatened terrestrial orchid Bletia purpurea. Plant Cell Tiss. Org. Cult. 94: 11-21.

Hossain MM (2008) Asymbiotic seed germination and in vitro seedling development of Epidendrum ibaguense Kunth. (Orchidaceae). African J. Biotechnol. 7(20): 3614-3619.

Johnson TR and Kane ME (2007) Asymbiotic germination of ornamental Vanda in vitro germination and development of three hybrids. Plant Cell Tiss. Org. Cult. 91: 251-261.

Kauth PJ, Kane ME, Vendrame WA and Reinhardt AC (2008) Asymbiotic germination response to photoperiod and nutritional media in six populations of Calapogan tuberosus (Orchidaceae): Evidence for ecotypic differentiation. Ann. Bot. 102: 783-293.

Kauth PJ, Vendrame WA and Kane ME (2006) In vitro seed culture and seedling development of Calopogon tuberosus. Plant Cell Tiss. Org. Cult. 85: 91-102.

Khosravi AR, Kadir MA, Kazemin SB, Zaman EQ and De Silva AE (2008) Establishment of a plant regeneration system from callus of Dendrobium cv. Serdang Beauty. African J. Biotechnol. 7(22): 4093-4099. 
Machaka HN, Al-zein MS, Westbury DB and Talhouk SN (2012) Reproductive success of the rare endemic Orchis galilaea (Orchidaceae) in Lebanon. Turkish J. Bot. 36: 677-682.

Mahendran G, Muniappan V, Ashwini M, Muthukumar T and Narmatha Bai (2013) Asymbiotic seed germination of Cymbidium bicolor Lindl. (Orchidaceae) and the influence of mycorrhizal fungus on seedling development. Acta Physiol. Plantarum 35: 829-840.

Manrique JP, Lizarazo CF and Silva AS (2005) Evaluation of the effect of three growth regulators in the germination of Comparettia falcata seeds under in vitro conditions. In Vitro Cell Dev. Biol. Plant 41: 838-843.

Marnique JP and Gutierrez YM (2006) Asymbiotic germination of Odontoglossum gloriosum Rchb. F. (Orchidaceae), under in vitro conditions. In Vitro Cell Dev. Biol. Plant. 42: 543-547.

Mitchell RB (1989) Growing hardy orchids from seeds at Kew. The Plantsman 11: 152-169.

Nanekar V, Shriram V, Kumar V and Kavikishor PB (2014) Asymbiotic in vitro seed germination and seedling development of Eulophia nuda Lindl. An endangered medicinal orchid. Proc. Natl. Acad. Sci. India Sect. B Biol. Sci. 84(3): 837-846.

Pant B and Thapa D (2012) In vitro mass propagation of an epiphytic orchid Dendrobium primulinum Lindl. through shoot tip culture. African J. Biotechnol. 11(42) 9970-9974.

Pyati AN and Murthy HN (1999) Embryo culture and seedling development of Aerides crispum Lindl. (Orchidaceae). J. Indian Bot. Sci. 78: 147-149.

Sgarbi E, Grimaudo M and Del Prete C (2009) In vitro asymbiotic germination and seedling development of Limodorum abortivum (Orchidaceae). Plant Biosystems 143(1): 114-119.

Shibu SB, Devi CB, Wesley SP and Moin S (2012) Ex situ conservation of endemic orchids of Western Ghats, Tamilnadu, India via asymbiotic seed germination. Advances in Applied Science Research 3 (5): 3339-3343.

Stewart SL and Kane ME (2006) Asymbiotic seed germination and in vitro seedling development of Habenaria macroceratitis (Orchidaceae) a rare Florida terrestrial orchid. Plant Cell Tiss. Org. Cult. 86: 147-158.

Sunkumlong and Deb CR (2008) Effect of different factors on immature embryo culture, PLBs differentiation and rapid mass multiplication of Coelogyne suaveolens (Lindl.) Hook. Indian J Exp. Biol. 46: 243-248.

Swarts ND and Dixon KW (2009) Terrestrial orchid conservation in the age of extinction. Ann. Botany 104: 543-556.

Warghat AR, Bajpai PK, Srivastava RB, Chaurasia OP, Chauhan RS and Sood H (2014) In vitro protocorm development and mass multiplication of an endangered orchid Dactylorhiza hatagirea. Turkish J. Botany 38: 737-746.

Yamazaki J and Miyoshi K (2006) In vitro asymbiotic germination of immature seed and formation of protocorm by Cephalanthera falcata (Orchidaceae). Ann. Botany 98: 1197-1206. 